\title{
n-3 Polyunsaturated fatty acids, inflammation and obesity-related disease
}

\author{
Lucy M. Browning \\ MRC Human Nutrition Research, Elsie Widdowson Laboratory, Fulbourn Road, Cambridge CB1 9NL, UK
}

\begin{abstract}
Obese individuals are at increased risk from a range of metabolic diseases, including insulin resistance, dyslipidaemia and hypertension. Adipose tissue is an important endocrine organ, secreting a range of inflammatory mediators, including tumour necrosis factor $\alpha$ and interleukin 6. Circulating concentrations of these cytokines are increased in obesity and may contribute to the pathogenesis of metabolic diseases. The present review considers the evidence linking inflammation and obesity-related disease. The data show that an inflammatory phenotype, measured by serum sialic acid concentration, identifies individuals with insulin resistance, dyslipidaemia and hypertension. Serum sialic acid concentration increases progressively in obese individuals with none, one or multiple features of the metabolic syndrome, independent of BMI. Supplementation with long-chain $n-3$ polyunsaturated fatty acids has shown anti-inflammatory effects in studies of both healthy populations and in models of chronic inflammatory conditions. The effect on insulin sensitivity has been varied, with both positive and negative effects. This variability may relate to the metabolic characteristics of the study population; individuals with high background inflammation may derive greater benefits from $n-3$ polyunsaturated fatty acid supplements, suggesting a possible interaction between diet and phenotype. Future research is needed to fully evaluate the role of anti-inflammatory strategies in the dietary management of obesity.
\end{abstract}

\section{n-3 Polyunsaturated fatty acids: Fish oil: Inflammation: Obesity}

The link between obesity and chronic disease is long established. Obese individuals are two to three times more likely to die prematurely than their lean counterparts (Calle et al. 1999), primarily due to the association between obesity and type 2 diabetes and CHD. BMI, a measure of obesity, is positively associated with the risk of developing insulin resistance in both men and women (Colditz et al. 1990; Chan et al. 1994). For an obese individual with a BMI of $30 \mathrm{~kg} / \mathrm{m}^{2}$ the risk of developing type 2 diabetes is increased thirteen times for men and twenty times for women relative to an individual with a BMI of $22 \mathrm{~kg} / \mathrm{m}^{2}$. Similarly, individuals with a BMI $>29 \mathrm{~kg} / \mathrm{m}^{2}$ have three times the risk of CHD relative to those with a BMI $<21 \mathrm{~kg} / \mathrm{m}^{2}$ (Manson et al. 1990). Central obesity, characterised by a preponderance of abdominal fat, is particularly associated with risk factors for $\mathrm{CHD}$, such as hypertension, type 2 diabetes and dyslipidaemia (Alexander, 2001).

Even though the literature documenting an association between obesity and disease is extensive, the pathogenesis is not fully understood. A range of mechanisms have been hypothesised, including an increase in non-esterified fatty acids contributing to insulin resistance (Frayn, 2001), an increase in autonomic nervous system activity, which is associated with hypertension and dyslipidaemia (Landsberg, 1999), and dysregulation of the hypothalamic-pituitaryadrenal axis, which may be associated with each aspect of the metabolic syndrome (Andrews \& Walker, 1999; Bjorntorp \& Rosmond, 2000). Recently, it has been recognised that adipose tissue itself is an important endocrine organ and actively secretes many substances into the circulation, including complement factors, prostaglandins and soluble receptors (Fruhbeck et al. 2001). Many of these substances are involved in inflammation, and emerging evidence suggests that inflammation is an important modulator of obesity-related disease.

\section{The role of inflammation}

There is a positive association between adiposity and the levels of circulating cytokines. It has been shown in human subjects that plasma levels of the cytokine tumour necrosis factor (TNF) $\alpha$ are associated with obesity (Tsigos et al. 1999)

\footnotetext{
Abbreviations: CRP, C-reactive protein; CVD, cardiovascular disease; IL, interleukin; PUFA, polyunsaturated fatty acids; TNF, tumour necrosis factor. Corresponding author: Lucy M. Browning, fax +44 1223 437515, email Lucy.Browning@mrc-hnr.cam.ac.uk
} 
and decrease with weight loss (Kern et al. 1995; Dandona et al. 1998). Adipose tissue expression and secretion of TNF- $\alpha$ and interleukin (IL) 6 are also increased in obesity (Kern et al. 2001). This factor may explain the specific association between central fat and disease, since abdominal obesity is specifically associated with increases in cytokine concentrations in addition to the effects of body weight (Tsigos et al. 1999). It has been estimated that abdominal adipose tissue may produce up to three times as much IL-6 as subcutaneous adipose tissue (Fruhbeck et al. 2001).

During acute infection or injury cytokines (IL-6 and TNF- $\alpha$ ) are released from the site of tissue injury and promote an acute-phase response. The acute-phase response is characterised by production of a range of proteins, primarily from hepatocytes but also from other cells such as monocytes, fibroblasts and adipocytes. These proteins, including $\mathrm{C}$-reactive protein (CRP) and orosomucoid are involved in tissue repair, clearance of cellular debris and killing of infectious agents and can be raised by up to 100 -fold above normal levels. Chronic low-grade inflammation, characterised by a less extreme elevation of acute-phase proteins, has been associated with a number of obesity-related health risks: peripheral vascular disease (Ridker et al. 2001); myocardial infarction (Danesh, 1999); hypertension (Chae et al. 2001); insulin resistance (Yudkin et al. 1999); type 2 diabetes (Pradhan et al. 2001); dyslipidaemia (Ridker et al. 2000). A prospective 7-year follow-up study examined the development of type 2 diabetes in individuals who had baseline measures for the acute-phase protein markers sialic acid and orosomucoid. Those individuals with baseline inflammation levels above the median were approximately four times more likely to develop type 2 diabetes based on sialic acid and approximately eight times more likely to develop type 2 diabetes based on orosomucoid (Schmidt et al. 1999). There is also evidence for the role of CRP as a predictor of disease. For example, a 3-year follow-up study of apparently healthy women showed that those with CRP concentrations in the highest quartile had a 4.4-fold increased risk of having a cardiovascular event when compared with those with concentrations in the lowest quartile (Ridker et al. 2000).

To date, evidence for a direct pathogenic role for inflammation in disease is limited. The TNF- $\alpha$-knockout mouse model showed improved insulin sensitivity relative to wildtype mice when both were placed on a high-fat diet to induce obesity (Uysal et al. 1997). Using the ob/ob mouse model, a TNF- $\alpha$ receptor-knockout mouse was also created. In this model of a more severe genetic form of obesity mice with no functional TNF- $\alpha$ had significantly higher $(P<0.001)$ insulin sensitivity relative to that of the control $o b / o b$ mice, although the improvement was not to the same extent as in the previous study (Uysal et al. 1997). These studies suggest that, in mice, TNF- $\alpha$ is a key link between obesity and insulin resistance. This finding may suggest a role for inflammation, although TNF- $\alpha$ may also reduce non-esterified fatty acids, improve glucose transport by increasing glucose transporter 4 expression and improve insulin receptor signalling, which may contribute to the reduction in disease. In human subjects, however, anti-TNF- $\alpha$ therapy in patients with type 2 diabetes had no impact on insulin sensitivity (Ofei et al. 1996).
Table 1. Variability in acute-phase response markers measured on three to six occasions in fifteen overweight men and women and the correlation with serum sialic acid

\begin{tabular}{lcc}
\hline $\begin{array}{l}\text { Acute-phase } \\
\text { response marker }\end{array}$ & Fratio & $\begin{array}{c}R^{2} \text { (with serum } \\
\text { sialic acid) }\end{array}$ \\
\hline Sialic acid & $37 \cdot 1^{\star \star \star}$ & \\
Orosomucoid & $19 \cdot 8^{\star \star \star}$ & $0 \cdot 716^{\star \star \star}$ \\
C-reactive protein & $10 \cdot 3^{\star \star \star}$ & $0 \cdot 672^{\star \star \star}$ \\
$\alpha_{1}$-Antichymotrypsin & $6 \cdot 7^{\star \star \star}$ & $0 \cdot 308^{\star \star \star}$ \\
\hline
\end{tabular}

${ }^{* *} P<0.0001$.

In order to be able to understand the relationship between obesity and inflammation it is important to have a reliable measure of habitual inflammatory status. A number of markers of acute-phase response have been used as measures of inflammatory status, but the ability of a single measure to appropriately reflect habitual status has not been assessed. Sialic acid, CRP, orosomucoid and $\alpha_{1}$-antichymotrypsin were measured on three to six occasions in fifteen overweight men and women to identify a marker with the least variability that would provide a useful measure of habitual status (Browning et al. 2001). Table 1 shows the $F$ ratio for each marker and the correlation with sialic acid. This analysis demonstrates that sialic acid provides the most reliable measure of habitual status when comparing interand intra-individual variability in overweight subjects. Each of the other acute-phase proteins measured correlated well with sialic acid, indicating that it is representative of the overall acute-phase response. This result is not surprising, as sialic acid is not an acute-phase protein but the terminal glycoprotein found as part of many acute-phase proteins. Thus, measuring serum sialic acid provides a useful biological measure of the overall acute-phase response and may be useful when defining status.

It is noteworthy that sialic acid is more stable than CRP, which has been widely used in many epidemiological analyses. A number of studies have shown that CRP is an important predictor of cardiovascular disease (CVD; Ridker et al. 2000; Ridker, 2001) and type 2 diabetes (Festa et al. 2002). The greater day-to-day variability in CRP relative to sialic acid would tend to reduce the agreement with longterm health outcomes, suggesting that inflammation may be a more important determinant of disease than previously recognised. There is, however, much less data on sialic acid.

To date, sialic acid has been shown by multiple regression analysis to be independently related to individual features of the metabolic syndrome: blood pressure; plasma insulin; serum cholesterol (Crook et al. 1998). The incremental association between sialic acid and multiple features of the metabolic syndrome was examined in a communitybased study of 263 overweight women (Krebs et al. 2003). Subjects were excluded if they had symptoms of intercurrent infection, known diabetes, treated dyslipidaemia, a chronic inflammatory condition, liver disease, malignancy, smoked more than twenty-five cigarettes per day or had an alcohol intake of more than twenty-five units per week. Individuals were grouped based on the presence or absence of three additional features of the metabolic syndrome: insulin resistance (defined as a homeostasis model 


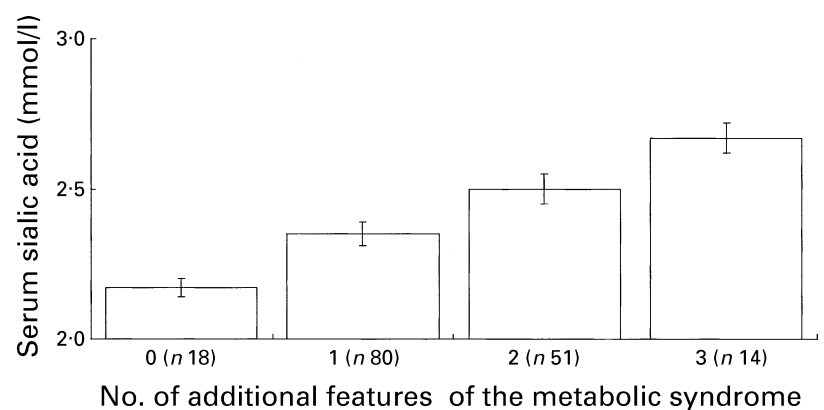

Fig. 1. Serum sialic acid concentration in 263 overweight women grouped according to the absence (0) or presence of additional features of the metabolic syndrome: insulin resistance; dyslipidaemia; hypertension (1-3). Values are means with their standard errors represented by vertical bars.

assessment value in the top tertile for the group); dyslipidaemia (defined as a fasting triacylglycerol level of $>1.7 \mathrm{mmol} / \mathrm{l}$ ); hypertension (defined as systolic and diastolic readings of $>160$ and $>90 \mathrm{mmHg}$ respectively). The mean sialic acid concentration for each group was calculated. The number of subjects and the mean sialic acid concentrations for each of the groups are shown in Fig. 1. Linear regression analysis demonstrated a strong positive association between sialic acid and body weight, fatness, insulin resistance, dyslipidaemia and hypertension $(P<0 \cdot 0001)$. Additionally, from an ordinal logistic regression model, there was a highly significant $(P<0 \cdot 001)$ incremental association with none, one or multiple features of the metabolic syndrome. The odds ratio for multiple features of the metabolic syndrome compared with one or no feature was 2.7 times when sialic acid concentrations increased by $1 \mathrm{SD}$ or $0.34 \mathrm{mmol} / 1$ (the model was adjusted for age, cigarette smoking status, alcohol consumption status, menopausal status, oral contraceptive and hormonereplacement therapy use). When further adjusted for BMI, the trend was attenuated but remained highly significant, with the odds ratio being 2.3 times for a 1 SD increase in sialic acid.

Although further data are needed in large cohorts, with hard end points, these preliminary data suggest that inflammation is an important modulator of obesity-related disease. This finding raises the possibility that dietary strategies can be used to decrease inflammation and improve disease outcome, independent of body weight.

\section{Polyunsaturated fatty acids and obesity-related disease}

In recent years there has been a shift in the relative proportions of different fatty acids in the diet. Reductions in saturated fat have been counterbalanced, in part, by increases in $n-6$ polyunsaturated fatty acid (PUFA). The value for $n-6: n-3$ PUFA has increased from historical estimates of approximately $4: 1$ to current estimates of between 10:1 and 20:1 (Simopoulos, 1999). The n-6:n-3 PUFA value is of metabolic interest, as the two groups of fatty acids compete directly with one another for enzymes for elongation and desaturation and for incorporation into cells, where they are able to influence cell functions such as signalling pathways and receptor function.

There are various dietary sources of $n-3$ and $n-6$ PUFA. $\alpha$-Linolenic acid (a precursor $n-3$ PUFA) is found in green leafy vegetables, linseed and rapeseed oils, walnuts and Brazil nuts, while long-chain $n-3$ PUFA, especially eicosapentaenoic acid and docosahexaenoic acid, are found in marine or fish oils such as salmon, mackerel and herring. $\alpha$-Linolenic acid may exert its biological effects directly or through conversion to long-chain $n-3$ PUFA such as eicosapentaenoic acid and docosahexaenoic acid. $n-6$ PUFA occur mostly in the diet as linoleic acid and can be found in sunflower, safflower and maize oils and many fruits, vegetables, nuts, grains and seeds.

It has been suggested that changes in $n-6: n-3$ PUFA and the absolute amounts of both these types of fatty acids may be linked to the risk of many chronic diseases, e.g. CVD and inflammatory disorders such as rheumatoid arthritis, asthma and Crohn's disease (Department of Health, 1994; Grimble, 1998). Interest in both the total amount and the type of fat in the diet is now the focus of much research. Absolute increases in $n$-3 PUFA have been suggested to be beneficial for health (Simopoulos, 1999). There is substantial epidemiological evidence for a protective or beneficial effect of fish. Greenland Inuits, who have a high total fat intake, have surprisingly low rates of CVD and type 2 diabetes (Dyerberg \& Bang, 1979; Bjerregaard et al. 2000). However, evidence from human intervention studies for beneficial effects of long-chain $n$-3 PUFA is more limited. A recent meta-analysis examined the association between $n$-3 PUFA intake and risk of CHD. It was concluded that $n-3$ PUFA intake decreased overall mortality, deaths due to myocardial infarction and sudden death in patients with CHD (Bucher et al. 2002).

The potential mechanisms for the beneficial effects of $n-3$ PUFA on CVD risk relate to their hypotriacylglycerolaemic (Eritsland et al. 1994), anti-thrombotic (Vognild et al. 1998) and anti-fibrinolytic (Saynor \& Gillott, 1992) effects. It is also hypothesised that they have anti-inflammatory effects. In animal studies the anti-inflammatory effects of $n-3$ PUFA have been demonstrated by the measurement of the cytokines TNF- $\alpha$ and IL-6 (Mulrooney \& Grimble, 1993; Sadeghi et al. 1999). Human $n$-3 PUFA intervention studies have shown anti-inflammatory effects in patients with chronic inflammatory conditions such as rheumatoid arthritis (Geusens et al. 1994), asthma (Broughton et al. 1997), Crohn's disease (Belluzzi et al. 1996) and psoriasis (Mayser et al. 1998), and n-3 PUFA have been shown to alleviate symptoms of each disease. In healthy subjects decreases in pro-inflammatory cytokines such as TNF- $\alpha$ and IL-1 $\beta$ have been shown in both plasma (Caughey et al. 1996) and isolated cells (Endres et al. 1989). The anti-inflammatory effects of $n-3$ PUFA extend to specific functions of monocytes (Hughes, 1998) and neutrophils (Sperling, 1998). The anti-inflammatory actions of $n-3$ PUFA may be direct, such as their actions on transcription factors to influence gene expression, or mediated through eicosanoids. PUFA are incorporated into phospholipids and used to form eicosanoids, which have diverse biological functions in the coordination of immune and inflammatory processes. The eicosanoid formed is specific to the fatty 
acid from which it is derived, eicosapentaenoic acid forms prostaglandins of the 3 series and leukotrienes of the 5 series, while the $n-6$ PUFA arachidonic acid forms 2 series prostaglandins and 4 series leukotrienes. $n$-3 PUFA form weaker pro-inflammatory eicosanoids than $n-6$ PUFA, and altering the relative proportions of $n-3$ and $n$-6 PUFA in the diet therefore modulates the overall inflammatory environment (Lee et al. 1985).

If the link between obesity and CVD is modulated by inflammation, $n$-3 PUFA may offer a useful antiinflammatory dietary strategy to decrease obesity-related disease. This possibility has been tested in a controlled dietary intervention study by examining the differential impact of $n$-3 PUFA on CVD risk in groups with different inflammatory status (Browning et al. 2002). The subjects were female, premenopausal and non-diabetic, aged 19-51 years (mean 39 (SD 7) years) and had a BMI in the range $24-44 \mathrm{~kg} / \mathrm{m}^{2}$ (mean $30 \cdot 8(\mathrm{SD} 5 \cdot 1) \mathrm{kg} / \mathrm{m}^{2}$ ). Fasting blood samples were collected and serum sialic acid was measured in sixty-three women in order to determine their inflammatory status. Serum sialic acid concentrations ranged from 1.61 to $2.70 \mathrm{mmol} / \mathrm{l}$. Women in the top and bottom thirds of this population (see Fig. 2) were recruited to the randomised crossover study, representing groups with high and low inflammatory status respectively. Participants received five capsules daily providing either $n$-3 PUFA $(1.3 \mathrm{~g}$ eicosapentaenoic acid and $2.9 \mathrm{~g}$ docosahexaenoic $\mathrm{acid} / \mathrm{d})$ or a placebo $(2.8 \mathrm{~g}$ linoleic and $1.4 \mathrm{~g}$ oleic acid/d) for a period of 12 weeks for each treatment, with a 4-week washout between treatments. Detailed measures of CVD risk were made before and after each treatment period, including a five-point oral glucose tolerance test.

Preliminary analysis of this dataset has focused on insulin sensitivity. At baseline there were significant differences between the two groups, the group with the raised inflammatory status having significantly higher sialic acid,

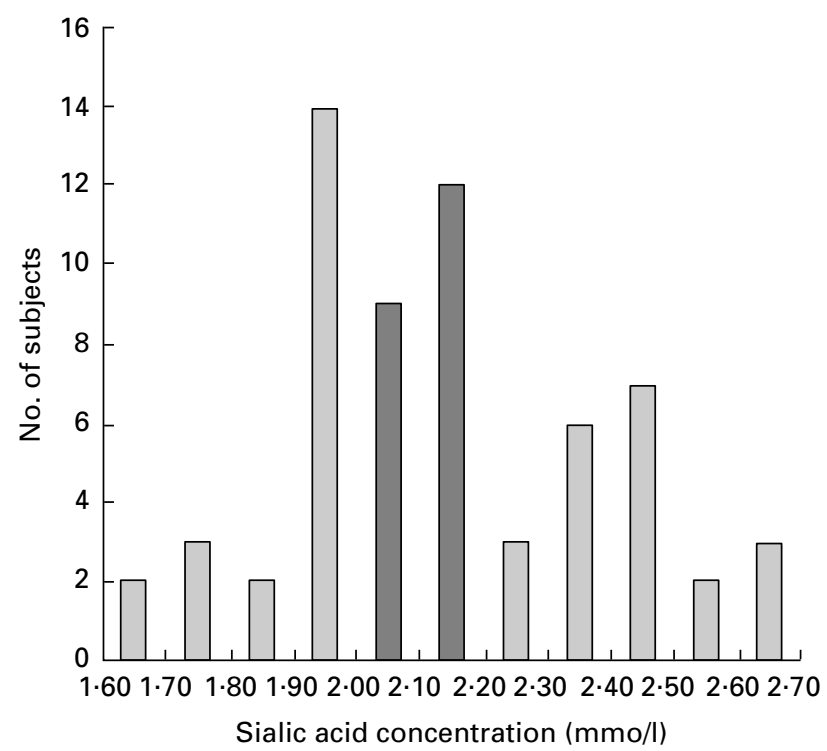

Fig. 2. Distribution of serum sialic acid concentrations in sixty-three women screened for participation in the $n$-3 PUFA intervention study, grouped into thirds. $\square$, Women not recruited to the study.
(2.19 (SD 0.25) v. 1.82 (SD 0.15) $\mathrm{mmol} / \mathrm{l} ; P<0.001)$, BMI (32.0 (SD 6.7) v. 28.0 (SD 5.7) $\mathrm{kg} / \mathrm{m}^{2} ; P<0.05$ ) and area under the insulin curve, calculated from the oral glucose tolerance test (35 663 (SD 30 784) v. 22796 (SD 10 091) $\mathrm{pmol} \cdot \mathrm{min} / \mathrm{l} ; \quad P<0 \cdot 01$ ), but no significant difference in fasting insulin, glucose, homeostasis model assessment or area under the glucose curve (Browning et al. 2002). These findings support previous evidence of the association between obesity-related disease and inflammatory status. Fig. 3 provides evidence of an interaction between inflammatory status and insulin sensitivity. n-3 PUFA supplementation was associated with a significant improvement in area under the insulin curve in the group with the raised inflammatory status $(P<0.05)$, whilst there was no significant improvement with the placebo treatment. There were no changes with $n-3$ PUFA or placebo in the low inflammatory status group. When comparing the effect of $n-3$ PUFA with that of the placebo treatment directly there was a significant difference between the final time points for each supplementation period, again only in the high inflammatory status group $(P<0 \cdot 05)$. There were no significant differences in weight, fasting glucose or insulin or area under the glucose or insulin curves during either the $n-3$ PUFA or placebo treatment individually or when comparing the treatment end points directly. The present study will go on to examine other aspects of CVD risk.

Previous studies have shown variable results when reporting effects of $n-3$ PUFA on insulin sensitivity. Animal studies have demonstrated protective effects of $n-3$ PUFA. For example, rats fed high-fat diets developed insulin resistance, while those fed high-fat diets also high in $n-3$ PUFA remain insulin sensitive (Storlien et al. 1987). In human studies no effect of $n$-3 PUFA on insulin sensitivity was shown in hypertensive subjects (Mori et al. 1999) but

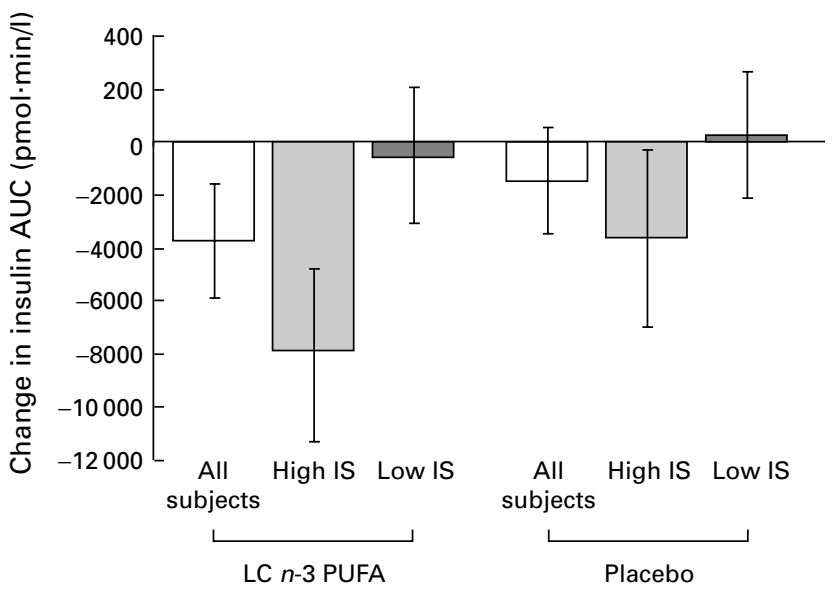

Fig. 3. Change in area under the curve (AUC) for insulin (final baseline) with $n-3$ polyunsaturated fatty acid (PUFA) and placebo supplementation for premenopausal non-diabetic female subjects aged 19-51 years, with BMI in the range $24-44 \mathrm{~kg} / \mathrm{m}^{2}$ who were grouped according to inflammatory status (IS; based on serum sialic acid $(\mathrm{mmol} / \mathrm{l})$; low IS $<2 \cdot 00$, high IS $>2 \cdot 20)$. LC, long-chain. Values are means with their standard errors represented by vertical bars. Mean value was significantly different from that for the placebo treatment: ${ }^{\star} P<0.05$. 
positive effects have been reported in hypertriacylglycerolaemic subjects (Eritsland et al. 1994). Results for diabetic subjects have been mixed, with both positive (McManus et al. 1996) and negative (Popp-Snijders et al. 1987; Vessby \& Boberg, 1990) effects. Our findings provide evidence to support a role for $n$-3 PUFA in improving insulin sensitivity. The design of the study, separating individuals by inflammatory status, also identifies a possible reason why some previous studies may not have shown marked improvements in insulin sensitivity with $n-3$ PUFA. It suggests that individuals with an inflammatory phenotype respond best to this type of strategy to improve the risk of obesity-related disease, and this factor may have important implications for the management of obese individuals.

The inflammatory phenotype identified in the present study, in terms of habitual serum sialic acid, presumably reflects an underlying inflammatory genotype. Several candidate genes that may influence inflammatory status have already been identified, for example, in the cytokines IL-6 and TNF- $\alpha$. These genotypes have not only been associated with chronic inflammatory conditions but also risk factors for CHD (Humphries et al. 2001) and insulin resistance (Dalziel et al. 2002). More recently, inflammatory genotypes have been shown to be associated with habitual inflammatory status, measured by serum CRP (Vickers et al. 2002).

\section{Conclusions}

Inflammation may be an important modulator of the relationship between obesity and the metabolic syndrome. Inflammatory status, identified using serum sialic acid, also shows a significant $(P<0 \cdot 001)$ incremental association with the presence of none, one or multiple additional features of the metabolic syndrome, suggesting that it may be a useful predictor of disease and premature mortality. Sialic acid is a more stable marker of the acute-phase response than the more commonly used high-sensitivity CRP.

The mechanisms through which obesity is associated with insulin resistance and CVD may in part be mediated through inflammation. There is now some preliminary evidence that dietary $n$-3 PUFA can modulate at least some aspects of disease risk. Further research into the mechanism of action of $n-3$ PUFA is required, but emerging data raise the possibility that the effect of $n-3$ PUFA is achieved in part through an anti-inflammatory mechanism. This integrated hypothesis is shown in Fig. 4 and has potentially important implications for the dietary management of obesity.

Although $n$-3 PUFA are probably the most extensively studied nutrients with anti-inflammatory actions, there is limited evidence that a number of other dietary components may also have similar effects, which may in part explain their beneficial effects on obesity-related disease. For example, monounsaturated fatty acids have been shown to improve insulin sensitivity (Vessby et al. 2001) and have anti-inflammatory effects (Yaqoob et al. 1998), and glycaemic index has been correlated with serum CRP in a cross-sectional study (Liu et al. 2002) and positively related to CHD risk in a 10-year follow-up (Liu et al.

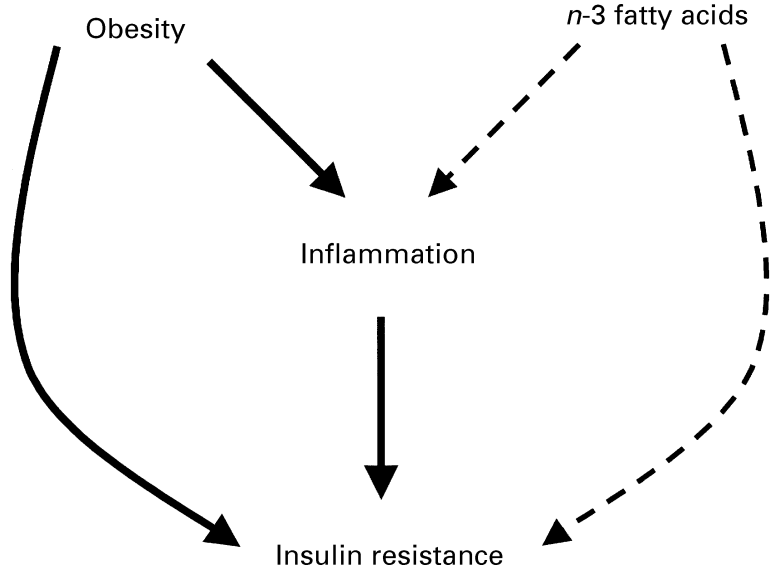

Fig. 4. The role of inflammation in obesity-related disease. Positive relationships (-); inverse relationships $(----)$.

2000). This area is an exciting one for future nutrition research.

\section{Acknowledgements}

The author would like to thank S. A. Jebb and J. D. Krebs for their supervision and comments on this review, M. A. O'Connell and C. A. Charalambos for their laboratory expertise and support, and all the volunteers who gave their time to participate in the studies. L. M. B. is supported by a Medical Research Council Studentship.

\section{References}

Alexander JK (2001) Obesity and coronary heart disease. American Journal of Medical Sciences 321, 215-224.

Andrews RC \& Walker BR (1999) Glucocorticoids and insulin resistance: old hormones, new targets. Clinical Science 96, 513-523.

Belluzzi A, Brignola C, Campieri M, Pera A, Boschi S \& Miglioli M (1996) Effect of an enteric-coated fish-oil preparation on relapses in Crohn's disease. New England Journal of Medicine 334, 1557-1560.

Bjerregaard P, Pedersen HS \& Mulvad G (2000) The associations of a marine diet with plasma lipids, blood glucose, blood pressure and obesity among the Inuit in Greenland. European Journal of Clinical Nutrition 54, 732-737.

Bjorntorp P \& Rosmond R (2000) The metabolic syndrome - a neuroendocrine disorder? British Journal of Nutrition 83, S49-S57.

Broughton KS, Johnson CS, Pace BK, Liebman M \& Kleppinger KM (1997) Reduced asthma symptoms with $n-3$ fatty acid ingestion are related to 5-series leukotriene production. American Journal of Clinical Nutrition 65, 1011-1017.

Browning LM, Krebs JK, O'Connell MA, Mishra GD \& Jebb SA (2002) n-3 PUFA supplementation improves insulin sensitivity in a group of overweight women with an inflammatory phenotype. Proceedings of the Nutrition Society 61, 123A.

Browning LM, O'Connell MA \& Jebb SA (2001) Inter- and intraindividual variability in acute phase response markers among overweight adults. Annals of Nutrition and Metabolism 45, Suppl. 1, 290. 
Bucher HC, Hengstler P, Schindler C \& Meier G (2002) n-3 Polyunsaturated fatty acids in coronary heart disease: a metaanalysis of randomized controlled trials. American Journal of Medicine 112, 298-304.

Calle EE, Thun MJ, Petrelli JM, Rodriguez C \& Heath CW Jr (1999) Body-mass index and mortality in a prospective cohort of U.S. adults. New England Journal of Medicine 341, 1097-1105.

Caughey GE, Mantzioris E, Gibson RA, Cleland LG \& James MJ (1996) The effect on human tumor necrosis factor alpha and interleukin 1 beta production of diets enriched in $n-3$ fatty acids from vegetable oil or fish oil. American Journal of Clinical Nutrition 63, 116-122.

Chae CU, Lee RT, Rifai N \& Ridker PM (2001) Blood pressure and inflammation in apparently healthy men. Hypertension 38, 399-403.

Chan JM, Rimm EB, Colditz GA, Stampfer MJ \& Willett WC (1994) Obesity, fat distribution, and weight gain as risk factors for clinical diabetes in men. Diabetes Care 17, 961-969.

Colditz GA, Willett WC, Stampfer MJ, Manson JE, Hennekens CH, Arky RA \& Speizer FE (1990) Weight as a risk factor for clinical diabetes in women. American Journal of Epidemiology 132, 501-513.

Crook M, Lumb P, Andrews V \& Swaminathan R (1998) Serum total sialic acid, a reputed cardiovascular risk factor, and its relationship to lipids, plasma fasting insulin, blood pressure and body mass index in normal individuals. Clinical Science 95, 53-57.

Dalziel B, Gosby AK, Richman RM, Bryson JM \& Caterson ID (2002) Association of the TNF-alpha-308 G/A promoter polymorphism with insulin resistance in obesity. Obesity Research 10, 401-407.

Dandona P, Weinstock R, Thusu K, Abdel-Rahman E, Aljada A \& Wadden T (1998) Tumor necrosis factor-alpha in sera of obese patients: fall with weight loss. Journal of Clinical Endocrinology and Metabolism 83, 2907-2910.

Danesh J (1999) Smoldering arteries? Low-grade inflammation and coronary heart disease. Journal of the American Medical Association 282, 2169-2171.

Department of Health (1994) Nutritional Aspects of Cardiovascular Disease. Report on Health and Social Subjects no. 46. London: H. M. Stationery Office.

Dyerberg J \& Bang HO (1979) Haemostatic function and platelet polyunsaturated fatty acids in Eskimos. Lancet ii, 433-435.

Endres S, Ghorbani R, Kelley VE, Georgilis K, Lonnemann G, van der Meer JW, Cannon JG, Rogers TS, Klempner MS \& Weber PC (1989) The effect of dietary supplementation with $n-3$ polyunsaturated fatty acids on the synthesis of interleukin-1 and tumor necrosis factor by mononuclear cells. New England Journal of Medicine 320, 265-271.

Eritsland J, Seljeflot I, Abdelnoor M, Arnesen H \& Torjesen PA (1994) Long-term effects of $n-3$ fatty acids on serum lipids and glycaemic control. Scandinavian Journal of Clinical and Laboratory Investigation 54, 273-280.

Festa A, D’Agostino R Jr, Tracy RP \& Haffner SM (2002) Elevated levels of acute-phase proteins and plasminogen activator inhibitor-1 predict the development of type 2 diabetes: the insulin resistance atherosclerosis study. Diabetes 51, 1131-1137.

Frayn KN (2001) Adipose tissue and the insulin resistance syndrome. Proceedings of the Nutrition Society 60, 375-380.

Fruhbeck G, Gomez-Ambrosi J, Muruzabal FJ \& Burrell MA (2001) The adipocyte: a model for integration of endocrine and metabolic signaling in energy metabolism regulation. American Journal of Physiology 280, E827-E847.

Geusens P, Wouters C, Nijs J, Jiang Y \& Dequeker J (1994) Longterm effect of omega-3 fatty acid supplementation in active rheumatoid arthritis. A 12 month, double blind, controlled study. Arthritis and Rheumatism 37, 824-829.
Grimble RF (1998) Dietary lipids and the inflammatory response. Proceedings of the Nutrition Society 57, 535-542.

Hughes DA (1998) In vitro and in vivo effects of $n-3$ polyunsaturated fatty acids on human monocyte function. Proceedings of the Nutrition Society 57, 521-525.

Humphries SE, Luong LA, Ogg MS, Hawe E \& Miller GJ (2001) The interleukin-6-174 G/C promoter polymorphism is associated with risk of coronary heart disease and systolic blood pressure in healthy men. European Heart Journal 22, 2243-2252.

Kern PA, Ranganathan S, Li C, Wood L \& Ranganathan G (2001) Adipose tissue tumor necrosis factor and interleukin-6 expression in human obesity and insulin resistance. American Journal of Physiology 280, E745-E751.

Kern PA, Saghizadeh M, Ong JM, Bosch RJ, Deem R \& Simsolo RB (1995) The expression of tumor necrosis factor in human adipose tissue. Regulation by obesity, weight loss, and relationship to lipoprotein lipase. Journal of Clinical Investigation 95, 2111-2119.

Krebs JD, Browning LM, Cooke JH, O'Connell MA, Mishra GD \& Jebb SA (2002) Elevated sialic acid predicts features of the metabolic syndrome. Diabetologia 45, A16.

Landsberg L (1999) Role of the sympathetic adrenal system in the pathogenesis of the insulin resistance syndrome. Annals of the New York Academy of Sciences 892, 84-90.

Lee TH, Hoover R, Williams JD, Sperling J, Raralese J, Spur BW, Robinson DR, Corey EJ, Lewis RA \& Austen KF (1985) Effect of dietary enrichment with eicosapentaenoic and docosahexaenoic acid on in vitro neutrophil and monocyte leukotriene generation and neutrophil function. New England Journal of Medicine 312, 1217-1224.

Liu S, Manson JE, Buring JE, Stampfer MJ, Willett WC \& Ridker PM (2002) Relation between a diet with a high glycemic load and plasma concentrations of high-sensitivity C-reactive protein in middle-aged women. American Journal of Clinical Nutrition $\mathbf{7 5}$, 492-498.

Liu S, Willett WC, Stampfer MJ, Hu FB, Franz M, Sampson L, Hennekens CH \& Manson JE (2000) A prospective study of dietary glycemic load, carbohydrate intake, and risk of coronary heart disease in US women. American Journal of Clinical Nutrition 71, 1455-1461.

McManus RM, Jumpson J, Finegood DT, Clandinin MT \& Ryan EA (1996) A comparison of the effects of $n-3$ fatty acids from linseed oil and fish oil in well-controlled type II diabetes. Diabetes Care 19, 463-467.

Manson JE, Colditz GA, Stampfer MJ, Willett WC, Rosner B, Monson RR, Speizer FE \& Hennekens CH (1990) A prospective study of obesity and risk of coronary heart disease in women. New England Journal of Medicine 322, 882-889.

Mayser P, Mrowietz U, Arenberger P, Bartak P, Buchvald J, Christophers E, Jablonska S, Salmhofer W, Schill WB, Kramer HJ, Schlotzer E, Mayer K, Seeger W \& Grimminger F (1998) Omega-3 fatty acid-based lipid infusion in patients with chronic plaque psoriasis: results of a double-blind, randomized, placebo-controlled, multicenter trial. Journal of the American Academy of Dermatology 38, 539-547.

Mori TA, Bao DQ, Burke V, Puddey IB, Watts GF \& Beilin LJ (1999) Dietary fish as a major component of a weight-loss diet: effect on serum lipids, glucose, and insulin metabolism in overweight hypertensive subjects. American Journal of Clinical Nutrition 70, 817-825.

Mulrooney HM \& Grimble RF (1993) The influence of butter, and corn, coconut and fish oils on the effects of recombinant human tumour necrosis factor alpha in rats. Clinical Science 84, 105-112.

Ofei F, Hurel S, Newkirk J, Sopwith M \& Taylor R (1996) Effects of an engineered human anti-TNF-alpha antibody (CDP571) on 
insulin sensitivity and glycemic control in patients with NIDDM. Diabetes 45, 881-885.

Popp-Snijders C, Schouten JA, Heine RJ, van der Meer J \& van der Veen EA (1987) Dietary supplementation of omega-3 polyunsaturated fatty acids improves insulin sensitivity in non-insulin-dependent diabetes. Diabetes Research 4, 141-147.

Pradhan AD, Manson JE, Rifai N, Buring JE \& Ridker PM (2001) C-reactive protein, interleukin 6, and risk of developing type 2 diabetes mellitus. Journal of the American Medical Association 286, 327-334.

Ridker PM (2001) High-sensitivity C-reactive protein: potential adjunct for global risk assessment in the primary prevention of cardiovascular disease. Circulation 103, 1813-1818.

Ridker PM, Hennekens CH, Burling JE \& Rifai N (2000) C-Reactive protein and other markers of inflammation in the prediction of cardiovascular disease in women. New England Journal of Medicine 342, 836-843.

Ridker PM, Stampfer MJ \& Rifai N (2001) Novel risk factors for systemic atherosclerosis: a comparison of C-reactive protein, fibrinogen, homocysteine, lipoprotein(a), and standard cholesterol screening as predictors of peripheral arterial disease. Journal of the American Medical Association 285, 2481-2485.

Sadeghi S, Wallace FA \& Calder PC (1999) Dietary lipids modify the cytokine response to bacterial lipopolysaccharide in mice. Immunology 96, 404-410.

Saynor R \& Gillott T (1992) Changes in blood lipids and fibrinogen with a note on safety in a long-term study of the effects of $n-3$ fatty acids in subjects receiving fish oil supplements and followed for seven years. Lipids 27, 533-538.

Schmidt MI, Duncan BB, Sharrett AR, Lindberg G, Savage PJ, Offenbacher S, Azambuja MI, Tracy RP \& Heiss G (1999) Markers of inflammation and prediction of diabetes mellitus in adults (Atherosclerosis Risk in Communities Study): a cohort study. Lancet 353, 1649-1652.

Simopoulos AP (1999) Essential fatty acids in health and chronic disease. American Journal of Clinical Nutrition 70, 560S-569S.

Sperling RI (1998) The effects of dietary $n-3$ polyunsaturated fatty acids on neutrophils. Proceedings of the Nutrition Society 57, $527-534$.
Storlien LH, Kraegen EW, Chisholm DJ, Ford GL, Bruce DG \& Pascoe WS (1987) Fish oil prevents insulin resistance induced by high-fat feeding in rats. Science 237, 885-888.

Tsigos C, Kyrou I, Chala E, Tsapogas P, Stavridis JC, Raptis SA \& Katsilambros N (1999) Circulating tumor necrosis factor alpha concentrations are higher in abdominal versus peripheral obesity. Metabolism 48, 1332-1335.

Uysal KT, Wiesbrock SM, Marino MW \& Hotamisligil GS (1997) Protection from obesity-induced insulin resistance in mice lacking TNF-alpha function. Nature 389, 610-614.

Vessby B \& Boberg M (1990) Dietary supplementation with $n-3$ fatty acids may impair glucose homeostasis in patients with non-insulin-dependent diabetes mellitus. Journal of Internal Medicine 228, 165-171.

Vessby B, Unsitupa M, Hermansen K, Riccardi G, Rivellese AA, Tapsell LC, Nalsen C, Berglund L, Louheranta A, Rasmussen BM, Calvert GD, Maffetone A, Pedersen E, Gustafsson IB \& Storlien LH (2001) Substituting dietary saturated for monounsaturated fat impairs insulin sensitivity in healthy men and women: The KANWU Study. Diabetologia 44, 312-319.

Vickers MA, Green FR, Terry C, Mayosi BM, Julier C, Lathrop M, Ratcliffe PJ, Watkins HC \& Keavney B (2002) Genotype at a promoter polymorphism of the interleukin- 6 gene is associated with baseline levels of plasma C-reactive protein. Cardiovascular Research 53, 1029-1034.

Vognild E, Elvevoll EO, Brox J, Olsen RL, Barstad H, Aursand M \& Osterud B (1998) Effects of dietary marine oils and olive oil on fatty acid composition, platelet membrane fluidity, platelet responses, and serum lipids in healthy humans. Lipids $\mathbf{3 3}$, 427-436.

Yaqoob P, Knapper JA, Webb DH, Williams CM, Newsholme EA \& Calder PC (1998) Effect of olive oil on immune function in middle-aged men. American Journal of Clinical Nutrition 67, 129-135.

Yudkin JS, Stehouwer CDA, Emeis JJ \& Coppack SW (1999) C-reactive protein in healthy subjects: associations with obesity, insulin resistance, and endothelial dysfunction. Arteriosclerosis, Thrombosis and Vascular Biology 19, 972-978. 